\title{
Eventscapes and the Creation of Event Legacies
}

\section{Graham Brown}

$\mathrm{PhD}$, Professor in Tourism Management

School of Management, University of South Australia

Email: graham.brown@unisa.edu.au

Address: GPO Box 2471, Adelaide, South Australia 5001, Australia

Tel: +61883020313

Fax: +61 883020512

\section{Insun Sunny Lee (corresponding author)}

$\mathrm{PhD}$, Lecturer in Event and Tourism Management

School of Management, University of South Australia

Email: sunny.lee@unisa.edu.au

Address: GPO Box 2471, Adelaide, South Australia 5001, Australia

Tel: +61 883027664

Fax: +61 883020512

\section{Katherine King}

$\mathrm{PhD}$, Senior Lecturer in Leisure Cultures

School of Tourism, Bournemouth University

Email: kingk@bournemouth.ac.uk

Address: Dorset House D114, Talbot Campus, Fern Barrow, Poole, BH12 5BB, UK

Tel: +44 1202968175

Fax: +44 1202515707

\section{Richard Shipway}

PhD, Associate Dean International Engagement

School of Tourism, Bournemouth University

Email: rshipway@ bournemouth.ac.uk

Address: Dorset House D233, Talbot Campus, Fern Barrow, Poole, BH12 5BB, UK

Tel: +44 1202965692

Fax: +44 1202515707 


\title{
Eventscapes and the Creation of Event Legacies
}

\begin{abstract}
Attention is directed to the difference in event legacies created by mega-events which often cause dramatic physical changes in urban environments and those which accompany events which leave very little imprint on the landscape where they are held. The Tour Down Under cycle race, which is held annually in South Australia, is examined as an example of the latter. The spatial pattern of the event and the range of settings which support it are presented as an eventscape by drawing on concepts such as Bale's (1994) sportscape and Bitner's (1992) servicescape. These interpretations are used to identify legacies. It is suggested that the creation of positive legacies requires communities that are part of the eventscape to engage in imaginative leveraging that is consistent with long-term strategic objectives. The paper offers a new definition of eventscape.
\end{abstract}

Keywords: Eventscape, Event legacies, Event impacts, Cycling events, Sport events

\section{Introduction}

An interest in behaviour associated with events from a geographical perspective (Brown, Hixson \& McCabe, 2013; Hall \& Page, 2014) is reflected in this paper which offers a new approach to the analysis of event legacies. Attention is directed to the spatial pattern and the impacts created by events such as cycle races which move through widely dispersed landscapes, and connect natural and cultural resources and local communities. The paper provides a conceptual discussion of eventscapes and uses the discussion to reveal impacts which may endure beyond the duration of the event. To illustrate the discussion, a case study of the Tour Down Under (TDU) in South Australia is presented. It is the first event of the annual Union Cycliste Internationale (UCI) series that culminates in the Tour de France which has been described as "a fluid sporting phenomenon that traverses the French landscape" (Lamont \& McKay 2012, p.314). With reference to Spinney's (2006) ethnographic study, Lamont and McKay (2012) described cycling on the route as "kinaesthetic submergence in the sportscape" (p.324).

The concept of eventscapes is used to identify the role of the environment in relation to event outcomes. At the TDU, the eventscape is created by the selection of routes, the location of support services and, importantly, levels of spectator activity and community participation. 
Although the term eventscape has featured in previous studies, it has mainly been used to describe an urban precinct which has become the setting for different types of events (Chang \& Huang, 2005; Furman, 2007) and, interchangeably, with the notion of permanent festivalization (Shaw, 2014). In this paper, eventscapes is used to describe the spatially dispersed nature of an event and the way the landscape represents an environmental resource and a series of inter-related places that are temporarily transformed by the event. Understanding the operation of eventscapes will enable research on event impacts and legacies to be advanced, and will assist stakeholders to more effectively manage event spaces to achieve desired outcomes.

Event legacies can be planned or unplanned, negative or positive and tangible or intangible (Gratton \& Preuss, 2008) and to date, most of the literature has focussed on legacy in relation to mega events (Davies, 2012; Minnaert, 2012) and transformations that result from large scale investments in stadia and urban infrastructure. This raises questions about whether events such as the TDU are able to create legacies when little physical evidence remains to indicate that an event has been held. It has been noted that translating intangible impacts into legacies is a challenge for event management (Preuss, 2007). However, there is a growing recognition that event legacies associated with psychic income and social capital, while not readily visible, may still be important. Prior to being applied in events, intrinsic rewards gained in employment such as emotional satisfaction and a sense of achievement had been cited as examples of psychic income (Reif, 1975). Burgan and Mules (1992) used the term to describe a welfare benefit as part of an economic impact study of the 1982 Commonwealth Games before an extended discussion of the concept was provided by Crompton (2004) who defined psychic income as the perception by residents of emotional and psychological benefits of an event. Kim and Walker (2012) used the dimensions suggested by Crompton to develop a multidimensional scale to measure psychic income. Their study generated a five factor structure comprising community pride associated with enhanced image, community attachment, pride related to infrastructure improvements, event excitement and community excitement. A recent study by Gibson, Walker, Thapa, Kaplanidou, Geldenhuys and Coetzee (2014) used four items to measure psychic income at the 2010 FIFA World Cup and found that the event produced a sense of community and pride. Interestingly, an earlier review by Gibson (1998) had suggested that small scale events might provide greater psychic income than major sport events. 
Positive outcomes for host communities such as an increase in connectedness among group members and a reduced sense of social alienation can enhance social capital which can serve as a resource for future actions (Gibson, 2011). In order to gain long-term benefits, events must be treated as windows of opportunity and, although, impacts may be the automatic effects of events (Smith, 2011), legacies must be leveraged. This implies the need for a proactive approach in which stakeholders can use events to achieve strategic objectives. By adopting creative forms of engagement, local residents can seek to achieve desired outcomes in the form of event legacies. It is in these contexts that it is important to consider the eventscape of the TDU and the opportunities it presents.

\section{The Tour Down Under}

During six days of racing in January, 2014 more than 762,000 people, including 36,000 interstate and international visitors (Events South Australia, 2014), adopted a spectatorial gaze (Urry \& Larsen 2011) of international teams as they competed in the TDU. Held in South Australia annually since 1999, it was the first race outside of Europe to be given UCI World Tour status and has become the largest cycling event in the southern hemisphere. It filled a void when the Formula 1 Grand Prix moved from Adelaide to Melbourne, and generates about AUS\$45.9 million for South Australia each year (Events South Australia, 2014). The race is owned and managed by Events South Australia which is part of the South Australia Tourism Commission and receives financial support from the state government. It attracts a large number of sponsors including Santos (oil and gas production), Skoda (car manufacture), the Cancer Council, BUPA (health insurance), University of South Australia (UniSA), Wolf Blass (wine producer) and a number of media and bicycle and bicycle equipment manufacturers. It has become very popular and has a loyal following among state residents who participate in large numbers at event-related activities such as street parties and charity challenges. In addition to the professional teams, the event attracts members of cycle clubs from across Australia, serious amateur cyclists and people who take part in mass participation recreational rides, such as the BUPA Challenge Tour. There are also special activities for children, many of which are designed to promote active, healthy lifestyles.

Adelaide is the host city for the race and the professional teams and most of the media stay at the Hilton International Hotel which acts as the race headquarters. Two races are held on street circuits in the centre of Adelaide but six race stages are held throughout the state of 
South Australia. After each stage, the teams return to the city where fans are able to interact with the professional cyclists. This is made possible due to the proximity of the city to the regional routes. The Tour Village is situated in Victoria Square, opposite the Hilton Hotel and is a place of entertainment and where media interviews are conducted. Also at the Tour Village, team cars and equipment are stored giving spectators an opportunity to watch mechanics work and meet some of the professional competitors. Street parties are held at a number of locations in the city and at towns visited by the Tour. These generate a social atmosphere, opportunities for local businesses to leverage economic benefits and for sponsors and other event stakeholders to make connections with local communities.

In 2014, Stage $1(135 \mathrm{~km})$ was hosted by the Barossa Council in the Barossa Valley located $60 \mathrm{~km}$ northeast of Adelaide. It is a major wine-producing region and tourist destination. This stage, started in one of the regional towns and finished in another major town in the Barossa Valley region, went through the famous vineyards, showcasing the region and its landscape. Stage $2(150 \mathrm{~km})$ started in Prospect, an inner-city suburb in Adelaide, and finished in Stirling, a town in the hills east of Adelaide, presenting alternative views of the state's landscape. Stage $3(145 \mathrm{~km})$ provided an opportunity to go through steep climbs with Corkscrew Hill located $22 \mathrm{~km}$ East-North of the Adelaide. The route of Stage $4(18.5 \mathrm{~km})$ was from the inner-city suburb of Unley through the Adelaide Hills to Victor Harbor on the Fleurieu Peninsula (Figure 1). The route included spectacular coastal views. In Stage 5 (151.5 $\mathrm{km}$ ), the race passed through the vineyards of McLaren Vale, a wine region approximately 35 $\mathrm{km}$ south of Adelaide to the hilltop finish on Willunga Hill. The last stage, Stage $6(85.5 \mathrm{~km})$, was a city circuit race which showcased the Adelaide city landscape (Figure 2).

Figure 1 near here

Figure 2 near here

The impacts of the TDU are influenced by the wide range of event settings and the diverse physical environments which accommodate event activities. In combination with eventrelated services, this represents the eventscapes of the TDU.

\section{Events and the Notion of '-scape'}


A landscape describes both the physical features and environments of the bounded spaces for action (Branton, 2009) and, the notion of a '-scape', as extracted from landscape (Aldrich 1966), can refer to the representation of a view (Hall 2008) and act as a framework for scenic interpretation (Gration et al. 2011). It has been used to reflect the role of environmental variables in different contexts and the relationships between humans and the environment associated with the symbolic role of space (Branton, 2009). In services marketing, servicescapes, make reference to the role of environmental variables and service attributes in the way consumer experiences are produced and consumed (Bitner 1992). The concept has been studied in various service situations, including casinos (Lucas 2003), restaurants (Ryu \& Jang 2007; Harris \& Ezeh 2008; Kim \& Moon 2009), airports (Newman 2007), sport facilities (Wakefield, Blodgett \& Sloan 1996), convention centres (Siu, Wan \& Dong 2012) and cafés (Hall et al. 2010). It has also been extended to more expansive settings where natural elements feature prominently such as wineries and vineyards (McDonnell \& Hall 2008), and outdoor festivals (Lee et al. 2008; Mason \& Paggiaro 2012). The context-specific setting of some servicescape studies has been evident by the use of terms such as winescape (Bruwer \& Lesschaeve 2012), sportscape, for built sport facility environments (Wakefield et al. 1996), storyscape, for heritage interpretation (Chronis 2005) and festivalscape, for the physical surroundings and atmosphere of festivals (Mason \& Paggiaro 2012). Consumptionscape and experiencescape have been used to describe the relationship between place and consumptive practices (Hall \& Page, 2014), but festivalscape and sportscape have been most directly related to the spatial setting of event experiences.

Festivalscapes has been used as the title of a map which identifies the location of festivals in a region of Norway (Jaeger \& Mykletun 2009) but the term festivalscape is normally used to describe the environmental setting of festivals. The physical environment and both tangible and intangible factors in the creation of a festival atmosphere were studied by Mason and Paggiaro (2012). Drawing on the concept of servicescape, festivalscape was first proposed by Lee et al. (2008) as a way of identifying the factors that can affect a visitor's festival experience. However, it was mainly services that were included such as program content, staff demeanour, facility provision, perceptions of food quality and information availability. A number of recent studies have discussed festivalscapes, but most have adapted measures of service attributes from retail settings used in urban settings and focused on examining the marketing aspect of festivals, such as the effect of fesitivalscape on visitor satisfaction and 
behavioural intentions (Bruwer 2013; Mason \& Paggiaro 2012; Yang, Gu and Cen 2011). Mason and Paggiaro (2012) explored the importance of the festivalscape in determining emotions, satisfaction and future behaviour of event visitors at food and wine events in Italy, using three attributes of festivalscape: food, fun and comfort. Yang, Gu and Cen (2011) used ambient conditions, facility aesthetics, layout, staff service, and the program to test the moderating effect of festivalscape on behavioural intentions at a cultural food festival in China. Recently, Bruwer (2013) examined the effect of festivalscape on a different type of dependent variable: the purchase of wine at a wine festival.

The literature which makes reference to eventscapes is quite varied and has discussed the creation of memory and meanings through the production and consumption of event experiences at particular places. Chang and Huang (2005) examined the (re)creation of social memories as a product of builtscapes, eventscapes and artscapes in Singapore. Foley, McPherson and McGillivray (2009) also chose Singapore as the setting for a case study about eventscapes and the creation of symbolic meanings of place. Shaw (2014) drew on the work of Appadurai (1997) and provided examples of translocal eventscapes associated with ethnic festivals in Toronto and London. Our paper seeks to further develop understanding of eventscape by moving the discussion to dispersed communities in rural landscapes and by discussing the way characteristics of the physical environment influence both the event experience and the spatial pattern of event impacts. Consequently, for events such as marathons, car rallies and cycling races which exhibit a dispersed pattern of spatial engagement, we define an eventscape as the combination of settings which facilitate and add value to the event ranging from sites which are modified to meet event needs and accommodate physical structures and services to scenic backdrops which may be unaffected by the event. Of key concern are the relationships that are created across the eventscape.

\section{The Eventscape of the Tour Down Under}

The eventscape is considered to be part of the cultural landscape (Cosgrove, 1989) and, consistent with Tuan's (1974) phenomenological geography, as an environment replete with signs that require interpretation. The conceptualisation that is applied in relation to the TDU draws on Bale's (1994) discussion of the modern sports landscape which viewed it as natural environment, human habitat, artifacts, systems, ideology, place experience and aesthetic. 
Ideas contained in Bale's discussion are used to show how the eventscape can be analysed from a number of different perspectives.

Perspective 1. The physical properties of the environment can be used as the starting point to define an eventscape, its boundaries and the type of markers that identify them. The notion of hard and soft spatial limits (Bale 1994) assists in identifying the characteristics of places that form part of the eventscape. In the case of the TDU, decisions about route selection play a central role in determining the boundaries and the location of markers. There is considerable variability in the amount of space devoted to the TDU with a lack of clearly defined boundaries along many of the routes. However, this is not the case at the start and finish which are very clearly defined with behaviour controlled by physical structures and design features. These hard and soft spatial limits can influence accessibility for spectators, proximity to the competitors and the suitability of places for commercial activities. At locations with soft spatial limits, visitors are able to move freely and find places which match their needs and, by doing so, they define some of the boundaries. Thus, the behaviour and appearance of spectators gives colour and form to the eventscape as illustrated in Figure 3 and 4. Significantly, the spatial scope of the eventscape can also be extended by local businesses, such as restaurants and entertainment venues which take advantage of opportunities to offer event-themed activities and services. The involvement of local businesses in events can be part of a strategy to leverage the benefits of hosting an event (Chalip 2004).

Figure 3 near here

Figure 4 near here

Perspective 2. The natural environment, as a physical system, can have a considerable impact on the eventscape and stakeholder experiences. The visual attributes of the landscape affect event planning in the recognition that the spectator experience and the quality of media coverage are enhanced when the race moves through a scenic vineyard or when the sea offers a colourful backdrop. Hills add challenges for competitors and vistas for spectators. Lee and his colleagues (2009) found that the natural environment positively affected the emotional value of festival participation and this strongly contributed to festival satisfaction and behavioural intentions. In contrast to indoor sport facilities, the natural environment cannot 
be controlled and the unpredictability of weather and road conditions can make the event more exciting and memorable.

Perspective 3. The natural environment is subject to temporary transformations, caused by the event although Bale (1994) has proposed that while nature can be used for sport it cannot be sportised in any permanent sense. Places are transformed to become the eventscape of the TDU but when the event is over they do not become permanent eventscapes. A wide range of physical infrastructure is transformed by the TDU and, in addition to temporary road closures during the race, some key stretches of road have been improved to create better racing conditions and reduce safety concerns. Local towns, which host the start or finish of a stage, become eventscapes by erecting street barricades, marking the route of the race, setting up street decorations, and providing entertainment. A competition is held each year with prizes awarded to the best dressed town and the best dressed street.

These spatial transformations are important as they provide a vehicle for community engagement and to showcase the region to external audiences. The geographical and cultural distinctiveness of the regions that the race passes through can be captured and the images of landscape and lifestyle can be promoted. Palmer (2010) has commented that the Tour de France provides a visual representation of an iconic France. It is important to recognise that all the transformations are the product of conscious decisions and, potentially competing, stakeholder agendas. So, the authors of the changes, the reasons for their actions and the intended beneficiaries need to be identified to understand the operation of the eventscape.

Perspective 4. An analysis of visual features and symbols that form part of the eventscape makes possible an ideological interpretation of the event. Events, including the TDU, create and use the symbolic visual features as a way to generate new spaces of consumption and to promote and differentiate place and event images. The appropriation and interpretation of the symbolic resources is fundamental to the success of events (Palmer 1998) and, at the TDU, bikes, in every conceivable form, illuminate the eventscape (see Figure 5 and 6). The race symbols can generate emotional responses as the eventscape becomes a distinct experiential space or liminal zone; set aside for a special purpose (Getz 2007). The display of appropriate symbols makes it possible to communicate a sense of identity with the TDU and this technique is actively exploited by event sponsors. 
Figure 5 near here

Figure 6 near here

Perspective 5. During the race, the eventscape is populated by a wide range of stakeholders and an analysis of the profile and numbers of people at the different locations will inform understanding of the event, its impacts and the nature of place experiences. The duration and intensity of the event experience varies greatly across the eventscape. The start and finish lines, the Tour Village in the centre of Adelaide and at places such as the Hilton hotel, attract large numbers of race officials, sponsors, media and spectators. In their colourful costumes, the crowd make a highly visible contribution to the eventscape at these locations which also include the provision of merchandise sales, sponsor gifts, live broadcasts, entertainment, and food and beverage services. In comparison, many remote locations attract no or only small numbers of spectators who wait patiently to gain a brief glimpse of the competitors as they speed past. The level of event service provision is at a minimum at such locations, and people do not stay long at the spot after the race passes. Thus, the behaviour varies from place to place and, as Lamont and McKay (2012) found in the Tour de France, some groups of people who are seriously involved in cycling participate by cycling along that day's Tour route before the race starts. They then wait at a certain point, such as a mountain or steep climb, like 'the King of the Mountains', for a view of the professional competitors before cycling to the next viewpoint.

Perspective 6. The eventscape can be treated as a series of servicescapes which have been designed to achieve particular outcomes. Services are provided for different programs in order to help different stakeholders meet their objectives. This may equate to achieving competitive success for the professional teams or meeting performance goals for competitors (Shipway \& Jones 2007; Getz \& Andersson 2010), the further development of a leisure career path for serious cyclists (Getz \& McConnell 2011), satisfaction and self-identify for participants of charity challenges (Snelgrove \& Wood 2010; Coghlan 2012), or authentic event experiences and socialisation with family and friends for spectators (Lamont \& McKay 2012). It is important to examine the extent to which the eventscape is used to gain these and other types of outcomes. 
Perspective 7. The eventscape, as a place of production, may help create a wide range of economic impacts and social impacts associated with income generation, relationship building and identity formation and these impacts may influence the long-term viability of the event. Thus, towns and cities need to become part of the eventscape to benefit from visitor spending and various forms of investment. Sponsors and other stakeholders can also have benefits, such as brand awareness, brand image enhancement and market interactivity (Meenaghan 2001) and destination brands can be built through showcasing the geographical and cultural distinctiveness of the regions (Jago et al. 2003; Lee \& Arcodia 2011).

Having demonstrated that an examination of the eventscape can be used to draw attention to the spatial pattern of event activities, the implications for the creation of event legacies will be discussed.

\section{Legacies from an Eventscape}

People who live in regional locations, at a distance from metropolitan centres, are normally forced to travel long distances to witness and become part of international events but the TDU, an event that forms part of the UCI international series, visits communities around the state of South Australia. It is a successful event that engenders a sense of local pride and is strongly supported by local residents (in-business South Australia, 2013). It enlivens communities that become part of the eventscape and, as it is held each year, some communities are presented with repeat opportunities to be engaged, to learn from previous experiences and to build on legacies that have been created. An event like the TDU does not require large capital investment which accompanies the construction of permanent facilities. This means the event creates few tangible legacies and little direct employment from eventinduced projects. Neither does it disrupt normal patterns of life as is the case with many large events (Fredline, 2005; Cheng \& Jarvis, 2010). In fact, the way temporary structures are built and dismantled so quickly, often on the day of the race, is regarded as an appealing characteristic by many residents of the host communities (Guinness, 2014). However, as with many events, the TDU does realign economic activity within a region (Rosentaub, 2011) and legacies can be created by this realignment. The economic activity is not at the scale associated with mega-events but it does provide, potentially significant, opportunities for small, dispersed communities that are connected by the eventscape. This is consistent with the proposition that the creation of social networks can provide the greatest form of social 
capital (Gibson et al., 2014). A contrast between the social, economic and particularly geopolitical dynamics of mega-events and those of the TDU is noteworthy. The size of mega events serves to concentrate economic activity into a small geographic space with the implication that many local businesses are forced to compete for resources prior to and during the event. An event like the TDU may have fewer resources but they are distributed to widely dispersed communities that are part of the eventscape.

In addition to making internal connections, the eventscape creates a political realignment with external organisations and agencies. Whereas mega events can be used to place a host city on the world stage and influence its position in the global hierarchy (Minnaert, 2011), events like the TDU can help to better integrate peripheral communities with the relevant centre where government and business decision-makers are located. In the case of the TDU, Adelaide, the state capital, represents the centre in most situations but the event is also connected to a global audience of cycle enthusiasts, equipment manufacturers, media organisations and team sponsors. So, the TDU provides an opportunity for communities to be noticed, to establish strategic alliances, to become part of networks and to create relationships with relevant business, government and sport organisations (Robinson, 2011). It is important to recognise that this is phrased as an opportunity and, consequently, members of the community must first become aware of the opportunities and must then become actively engaged to take advantage of them. The type of response and its suitability is likely to vary between communities across the eventscape and will require what has been termed "imaginative leveraging" (Smith, 2011). A key part of this process involves using the event to achieve local ambitions; a bottom-up approach with inspiration provided at the neighbourhood level and the creation of legacies that reflect local needs and that are consistent with strategic community objectives. Examples of legacies include the relationships established by UniSA, as a sponsor of the TDU, with regional communities. The university reconnects with these communities throughout the year to promote its courses and research initiatives. Other examples are illustrated by "benefits of the TDU outside of the event itself but a direct result or influence of hosting the event in the Barossa" (Craig Grocke, personal communication, 2015). Information provided by the Economic Development Manager of the Barossa Region, Craig Grocke, included:

Visitation: The Visitor information Centre has experienced strong demand from recreational cyclists for maps of cycle routes and has noted an increase in repeat visitation. 
The latter includes people who took part in the BUPA Challenge Ride during the TDU and then returned with family and friends to ride the route again.

Business Development: There has been strong growth in cycle hire, bike sales and an increase in the number of accommodation businesses that provide bikes and e-bikes. The Seppeltsfield Road Business Alliance, comprising thirty local businesses, is supporting an initiative to fund a AUS\$2million extension of a cycle trail into Seppeltsfield.

Health and Lifestyle: The TDU has profiled cycling as a way to stay fit, healthy and to socialise and the local recreation centre (The Rex) has introduced a learn to ride and improve nutrition fitness class which will culminate in participation in the next BUPA Challenge Ride. With a significant number of young mums and schoolchildren taking part in the class, it is regarded as an example of the "sort of shift" needed to assist health and wellbeing in rural communities.

For communities to become noticed, they must use the event to raise awareness about the community, its objectives and the issues it faces by providing information to external organisations. Hence, the value of using the event to improve networks and to establish relationships with stakeholders such as government departments and event sponsors. But the flow of information should not be in one direction and legacies can be created if the awareness of local residents is raised in ways that could be transformative (Death, 2011). In the case of the TDU, the eventscape can be portrayed as a temporary setting for healthy practices that reflect emerging social and environmental trends. These practices are displayed by cyclists and their supporters who participate in charity events associated with the TDU. The attitudes and behaviour of local people may be influenced by these displays if local people decide to replicate these practices.

The lack of tangible legacies from an event such as the TDU could be addressed by creating permanent structures at places which have become key elements of the eventscape such as Hutt Street in the city where teams and supporters congregate and Wilunga Hill where cyclists compete to win the most important stage of the King of the Mountain competition. Features such as sculptures and the palm prints of race winners can become permanent markers and locations for event-related activities that can be held throughout the year. However, a lack of tangible evidence does not mean that the TDU does not create legacies. 
Those communities which take advantage of being part of the eventscape may gain legacies in the form of social capital if improved networks create a sense of local power (Gibson, 2011) and if a heightened level of awareness about healthy lifestyles and development of physical resources (Derom, VanWynsberghe \& Scheerder, 2015) encourages more people to cycle around their communities, on roads that were improved to meet the standards associated with an elite international event.

\section{Conclusion}

It is very difficult to fully understand the spatial dynamics of an event such as a cycle race that moves, almost invisibly at times, across an extensive landscape. This may be why studies that seek to offer a comprehensive assessment of the impacts caused by such events are absent from the academic literature. An appropriate analytical framework is required and a study of the Tour Down Under was used to further develop the concept of eventscapes and to examine its applicability to this type of event. As a case study, it was possible to describe distinctive characteristics of the event, which is held each year in South Australia. It was also possible to demonstrate that the eventscape was a product of event management decisions, community activities and spectator performances and these findings may help researchers understand the dynamic nature of environments at other events. The eventscape could be presented on a map as a combination of the race routes but it is more than this. It takes different forms according to the level of service provision at different locations and the extent to which places are populated by event stakeholders. Of critical importance are the spectators who, in many ways, define the boundaries of the eventscape by their behaviour. Consistent with Edensor's (2000) ideas about the performance of tourists and Green's (2001) analysis of the role of sport sub-cultures at events (Green, 2001), the spectators were found to add colour, create the atmosphere and provide many of the symbols that both make the event meaningful and project personal identities. Although the term, eventscape, has been used in the literature, it has not been defined. We offered a definition in this paper and attention was directed to its applicability for events in which competitors move through the landscape. But the relevance of the definition for other types of events which are held in multiple locations or transform various settings should be acknowledged. For instance, eventscapes are becoming increasingly important as cities design precincts to create a distinctive "look" for the duration of an event. Eventscape would include the precincts and other locations transformed by the event. 
The second challenge accepted by this paper was to identify the type of legacies that may be created by events such as cycle races. In particular, it responds to the need for a better understanding of the way events can be used to foster social initiatives and community development (Chalip, 2006). A contrast was made between the lack of information about this type of event and the large body of literature that exists about legacies associated with megaevents, particularly the Olympic Games. It was shown that, at the TDU, places can be connected across the eventscape and there are opportunities for communities to establish alliances with event stakeholders. However, although networks can be used to improve information flows, the creation of legacies still requires imaginative leveraging and the paper raises questions which could be addressed by further research. If, as has been suggested, psychic income may accrue to some communities as an event legacy, it would be valuable to examine whether this is most effectively facilitated by community activities such as participation in the best dressed town competition or when businesses engage with corporate event sponsors or when by individuals join charity cycle events. Longitudinal studies could seek to determine the resilience of any event-induced demonstration effects on participation in physical activities. The case study of the Barossa suggests people have been stimulated to become cyclists, to train for future events and adopt healthy lifestyles so, as advocated by Derom et al. (2015), it is important to track individuals in order "to examine pre- and postevent physical activity" (p. 43). Finally, the extent to which the eventscape serves to forge global connections could be examined, as is implied by the shirts worn by many of the spectators which indicate that they have attended other international events and are members of clubs that are located all around the world.

\section{References}

Aldrich, R. I. 1966. "The development of "-scape.", American Speech 41 (2): 155-157.

Appadurai, K. 1997. Modernity at large: Cultural dimensions of globalisation. Minneapolis: University of Mineapolis Press.

Bale, J. 1994. Landscapes of modern sport. Leicester: Leicester University Press. 
Bitner, M. J. 1992. "Servicescapes: The impact of physical surroundings on customers and employees." The Journal of Marketing 56 (2): 57-71.

Branton, N. 2009. "Landscape Approaches in Historical Archaeology: The Archaeology of Places.", In International Handbook of Historical Archaeology, edited by D. Gaimster, and T. Majewski, 51-65. New York: Springer.

Brown, G., E. Hixson. and V. S. McCabe. 2014. "Privileged mobility: employment and experience at the Olympic Games." Journal of Sport \& Tourism 18 (4): 265-286.

Bruwer, J. and I. Lesschaeve. 2012. "Wine Tourists' Destination Region Brand Image Perception and Antecedents: Conceptualization of a Winescape Framework." Journal of Travel \& Tourism Marketing 29 (7): 611-628.

Bruwer, J. 2013. "Service Quality Perception and Satisfaction in a New Zealand Festivalscape: Buying Behavior Effects." Tourism Analysis 18 (1): 61-77.

Burgan, B. and T. Mules. 1992. "Economic impacts of sporting events." Annals of Tourism Research 19: 700-710.

Chalip, L. 2004. "Beyond impact: a general model for host community event leverage." In Sport tourism: Interrelationships, impacts and issues, edited by B. W. Ritchie and D. Adair, 226-252. Clevedon: Channel View.

Chalip, L. 2006. "towards social leverage of sport events." Journal od Sport \& Tourism 11 (2): 109-127.

Chang, T. C. and S. Huang. 2005. "Recreating place, replacing memory: Creative destruction at the Singapore River." Asia Pacific Viewpoint 46 (3): 267-280.

Cheng, E. and N. Jarvis. 2010. "Residents' perception of the social-cultural impacts of the 2008 Formula 1 Singtel Singapore Grand Prix." Event Management 14 (2): 91-106. 
Chronis, A. 2005. "Constructing heritage at the Gettysburg storyscape." Annals of Tourism Research 32 (2): 386-406.

Coghlan, A. 2012. "An autoethnographic account of a cycling charity challenge event: Exploring manifest and latent aspects of the experience." Journal of Sport \& Tourism 17 (2): 105-124.

Cosgrove, D. 1989. "Geography is everywhere: culture and symbolism in human geography." In Horizons in Human Geography, edited by D. Cosgrove and R. Walford, 118-153. London: MacNillan.

Crompton, J. 2004. "Beyond economic impact: an alternative rationale for the public subsidy of major league sport facilities." Journal of Sport Management 18: 40-58.

Death, C. 2011. "Greening' the 2010 FIFA World Cup: environmental sustainability and the mega-event in South Africa." Paper presented at Sport Mega-Event Impacts, Leveraging and Legacies. Institute for Global Issues. Vancouver, British Columbia. November 11-12, 2011.

Derom, I., R. VanWynsberghe, and J. Scheerder. 2015. "Maintaining physical activity postevent? Case of the Tour of Flanders Cyclo in Belgium". Annals of Leisure Research 18 (1): $25-47$.

Edensor, T. 2000. "Staging tourism: Tourist as performers." Annals of Tourism Research, 27 (2): 322-344.

Events South Australia. 2014. Our story, viewed 27 November 2014, $<$ http://tourism.sa.gov.au/events.aspx>.

Foley, M., G. McPherson, and D. McGillivray. 2009. "Establishing Singapore as the events and entertainment capital of Asia: Strategic brand diversification". In International Perspectives of Festivals and Events: Paradigms of analysis, edited by J. Ali-Knight, M. Robertson, A. Fyall and A. Ladkin, 53-64. London: Elsevier. 
Fredline, E. 2005. "Host and guest relations and sport tourism." Sport in Society 8 (2): 263279.

Furman, A. 2007. "The street as a temporary eventscape." The International Journal of the Humanities 5 (9): 77-84.

Getz, D. 2007. Event studies: Theory, research and policy for planned events. Oxford: Butterworth-Heinemann.

Getz, D. and T. D. Andersson. 2010. "The event-tourist career trajectory: A study of highinvolvement amateur distance runners." Scandinavian Journal of Hospitality and Tourism 10 (4): 468-491.

Getz, D. and A. McConnell. 2011. "Serious sport tourism and event travel careers." Journal of Sport Management 25: 326-338.

Gibson, H. J. 1998. "Sport tourism: a critical analysis of research." Sport Management Review 1 (1): 45-76.

Gibson, H. J. 2011. "Psychic income, social legacy and social capital: mega event legacies." Paper presented at Sport Mega-Event Impacts, Leveraging and Legacies. Institute for Global Issues. Vancouver, British Columbia. November 11-12, 2011.

Gibson, H. J., M. Walker, B, Thapa, K, Kaplanidou, S, Geldenhuys, and W. Ccoetzee. 2014. "Psychic income and social capital among host nation residents: a pre-post analysis of the 2010 FIFA World Cup in South Africa." Tourism Management 44: 113-122.

Gration, D., C. Arcodia., M, Raciti. and R. Stokes. 2011. "The blended festivalscape and its sustainability at nonurban festivals." Event Management 15 (4): 343-359.

Gratton, C. and H. Preuss. 2008. "Maximising Olympic impacts by building up legacies." International Journal of the History of Sport 25 (14): 1922-1938. 
Green, B. C. 2001. "Leveraging subculture and identity to promote sport events." Sport Management Review 4: 1-20.

Guinness, R. 2014. "Only way is up for Tour Down Under." The Sunday Morning Herald, 25 January 2014, viewed 22 June 2015, <http://www.smh.com.au/sport/cycling/only-way-is-upfor-tour-down-under-20140124-31e7r.html> .

Hall, C. M. 2008. "Servicescapes, designscapes, branding, and the creation of place-identity: South of Litchfield, Christchurch." Journal of Travel \& Tourism Marketing 25 (3-4): 233250.

Hall, C. M. and J. Page. 2014. "Geography and the study of events." In The Routledge hand book of events, edited by S. Page and J. Connell, 148-164. Hoboken: Taylor and Francis.

Hall, C. M., J. Tipler., R. Reddy. and K. Rowling. 2010. "Coffee servicescapes: The design of cafe culture in New Zealand." In Coffee culture, destinations and tourism, edited by L. Jolliffe, 23-40. Bristol: Channel View Publications.

Harris, L. C. and C. Ezeh. 2008. "Servicescape and loyalty intentions: An empirical investigation." European Journal of Marketing 42 (3/4): 390-422.

in-business South Australia. 2013. "TDU draws 757,000 spectators, more TV exposure", inbusiness Scouth Australia, 29 January 2013, viewed 30 January 2013, <http://www.inbusiness.com.au/news/story/2013-January-29/14986>.

Jaeger, K. and R. J. Mykletun. 2009. "The festivalscape of Finnmark." Scandinavian Journal of Hospitality and Tourism 9 (2-3): 327-348.

Jago, L., L. Chalip., G. Brown., T. Mules. and S. Ali. 2003. "Building events into destination branding: Insights from experts." Event Management 8 (1): 3-14.

Kim, W. G. and Y. J. Moon. 2009. "Customers' cognitive, emotional, and actionable response to the servicescape: A test of the moderating effect of the restaurant type." International Journal of Hospitality Management 28: 144-156. 
Kim, W. and M. Walker. 2012. "Measuring the social impacts associated with Super Bowl XLIII: preliminary development of a psychic income scale." Sport Management Review 15: 91-108.

Lamont, M. and J. McKay. 2012. "Intimations of postmodernity in sports tourism at the Tour de France." Journal of Sport \& Tourism 17 (4): 313-331.

Lee, I. and C. Arcodia. 2011. "The role of regional food festivals for destination branding." International Journal of Tourism Research 13 (4): 355-367.

Lee, J., C. Lee. and Y. Yoon. 2009. "Investigating differences in antecedents to value between first-time and repeat festival-goers." Journal of Travel \& Tourism Marketing 26 (7): 688-702.

Lee, Y., C. Lee., S. Lee. and B. J. Babin. 2008. "Festivalscapes and patrons' emotions, satisfaction, and loyalty." Journal of Business Research 61: 56-64.

Lucas, A. F. 2003. "The determinants and effects of slot servicescape satisfaction in a Las Vegas hotel casino." UNLV Gaming Research \& Review Journal 7 (1): 1-17.

Mason, M. C. and A. Paggiaro. 2012. "Investigating the role of festivalscape in culinary tourism: The case of food and wine events." Tourism Management 33 (6): 1329-1336.

McDonnell, A. and C. M. Hall. 2008. "A framework for the evaluation of winery servicescapes: A New Zealand case." PASOS. Revista de Turismo y Patrimonio Cultural 6 (2): 231-247.

Meenaghan, T. 2001. "Understanding sponsorship effects." Psychology \& Marketing 18 (2): 95-122.

Newman, A. J. 2007. "Uncovering dimensionality in the servicescape: Towards legibility." The Service Industries Journal 27 (1): 15-28. 
Minnaert, L. 2011. "Inclusive community legacies and the Olympic Games: the role and responsibility of the International Olympic Committee." Paper presented at Sport MegaEvent Impacts, Leveraging and Legacies. Institute for Global Issues. Vancouver, British Columbia. November 11-12, 2011.

Minnaert, L. 2012. "An Olympic legacy for all? The non-infrastructural outcomes of the Olympic Games for socially excluded groups (Atlanta 1996-Beijing 2008)." Tourism Management 33: 361-370.

Palmer, C. 1998. "Le Tour du Monde: Towards an Anthropology of the Global Mega-event." The Australian Journal of Anthropology 9 (3): 265-273.

Palmer, C. 2010. 'We close towns for a living': spatial transformation and the Tour de France." Social \& Cultural Geography 11 (8): 865-881.

Preuss, H. 2007. "The conceptualization and measurement of mega sport event legacies." Journal of Sport \& Tourism 12: 207-228.

Reif, W. E. 1975. "Intrinsic versus extrinsic rewards: resolving the controversy." Human Resource Management 14 (2): 2-11.

Robinson, M. 2011. "Balancing sport and tourism: a third party mediator to ensure effective leveraging of mega events." Paper presented at Sport Mega-Event Impacts, Leveraging and Legacies. Institute for Global Issues. Vancouver, British Columbia. November 11-12, 2011.

Rosentaub, M. 2011. "Do sport mega events really matter? Another look for the Emperor's clothes before all policy analysts are banished to the tower for good." Paper presented at Sport Mega-Event Impacts, Leveraging and Legacies. . Institute for Global Issues. Vancouver, British Columbia. November 11-12, 2011.

Ryu, K. and S. Jang. 2007. "The effect of environmental perceptions on behavioral intentions through emotions: The case of upscale restaurants." Journal of Hospitality and Tourism Research 31 (1): 56-72. 
Shaw, S. 2014. "Faces, spaces and places: Social and cultural impacts of street festivals in consmopolitan cities." In The Routledge hand book of events, edited by S. Page and J. Connell, 401-414. Hoboken: Taylor and Francis.

Shipway, R. and I. Jones. 2007. "Running away from home: understanding visitor experiences and behaviour at sport tourism events." International Journal of Tourism Research 9 (5): 373-383.

Siu, N. Y. M., P. Y. K. Wan, and P. Dong. 2012. "The impact of the servicescape on the desire to stay in convention and exhibition centers: The case of Macao." International Journal of Hospitality Management 31 (1): 236-246.

Smith, A. 2011. "Leverage: a new model or merely a new justification for mega-event projects?" Paper presented at Sport Mega-Event Impacts, Leveraging and Legacies. Institute for Global Issues. Vancouver, British Columbia. November 11-12, 2011.

Snelgrove, R. and L. Wood. 2010. "Attracting and Leveraging Visitors at a Charity Cycling Event." Journal of Sport \& Tourism 15 (4): 269-285.

Spinney, J. 2006. "A place of sense: A kinaesthetic ethnography of cyclists on Mont Ventoux." Environment and Planning D: Society and Space 24 (5): 709-732.

Tuan, Y. F. 1974. "Space and place: humanistic perspective." Progress in Geography 6: 233246.

Urry, J. and J. Larsen. 2011. The tourist gaze 3.0. London: Sage.

Wakefield, K. L., J. G. Blodgett. and H. J. Sloan. 1996. "Measurement and Management of the Sportscape." Journal of Sport Management 10 (1): 15-31.

Yang, J., Y. Gu. and J. Cen. 2011. "Festival Tourists' Emotion, Perceived Value, and Behavioral Intentions: A Test of the Moderating Effect of Festivalscape." Journal of Convention \& Event Tourism 12 (1): 25-44. 
Figure captions

- Figure 1: Route map of Tour Down Under 2014 Stage 4 (source: South Australia Tourism Commission)

- Figure 2: Route map of Tour Down Under 2014 Stage 6 (source: South Australia Tourism Commission)

- Figure 3: spectators in a sparsely populated part of the route (source: Katherine King)

- Figure 4: Colourful spectators extending the eventscape (source: Graham Brown)

- Figure 5: A bike illuminating the eventscape (in Norwood) (source: Graham Brown)

- Figure 6: A cycling Kangaroo - symbolic connection between event and host (source: Graham Brown) 